\title{
RANKING OF SUSTAINABILITY CRITERIA FOR INDUSTRIAL SYMBIOSIS APPLICATIONS BASED ON ANP
}

\author{
Hacı Mehmet ALAKAŞ®1, Şeyda GÜR (D2), Evrencan ÖZCAN ${ }^{\circledR 1}$, Tamer EREN(D1* \\ ${ }^{1}$ Industrial Engineering Department, Faculty of Engineering, Kirikkale University, Kirikkale, Turkey \\ ${ }^{2}$ Organized Industrial Area Vocational School, Harran University, Sanliurfa, Turkey
}

Received 05 September 2019; accepted 07 September 2020

\begin{abstract}
Highlights
$>$ Effective criteria are evaluated for the sustainability of industrial symbiosis applications.

$>$ The analytical network process method, which is one of the multi-criteria decision-making methods, has been analyzed for the criteria that affect the problem for the first time in the literature.

Management policies, environmental conditions and economic criteria are found more effective on sustainable industrial symbiosis.
\end{abstract}

\begin{abstract}
Enterprises have started to establish partnerships both to use their internal resources efficiently and to increase their environmental performance. Partnerships and interoperability of enterprises with different processes enable them to benefit more from their benefits. Moving towards the local and regional economy, these partnerships that increase environmental and own resources have created industrial symbiosis practices. Industrial ecology fields are established in these applications. Both environmental and economic gains can be achieved through the efficient use of resources by enterprises and the minimization of wastes. For the sustainability of these partnerships to be established by enterprises, they need to analyze the measures they take internally. In this study, the concept of industrial symbiosis and the criteria that are effective for the sustainability of these industrial symbiosis are evaluated. Analytical network process method is used. Thus, the industrial symbiosis infrastructures to be established by enterprises have been enabled to move strategically.
\end{abstract}

Keywords: industrial symbiosis, ANP, industrial partnership, ecology.

\section{Introduction}

The concept of industrial symbiosis has been developed as a new industrial application in recent years. It is based on a mutual benefit relationship between manufacturers and consumers in the industry. It is aimed at the efficient and common use of resources. The main objectives of industrial symbiosis are to optimize material flow, reduce waste at the source, recycle waste, and provide energy recovery (World Energy Council, 2018; Aissani et al., 2019). Industrial symbiosis applications are open to sharing services or by-product resources between businesses (Chertow, 2007).

As the concept of sustainability is included in the industry, studies have begun to establish environmental and industrial balance. In today's world, where competitive conditions are getting harder, it is also crucial to use resources efficiently without harming the environment.
Enterprises that apply clean production with a zero-waste awareness constitute the basis of sustainable development. Enterprises producing clean production with a zero-waste awareness constitute the basis of sustainable development (Kurup \& Stehli, 2009). When acting in this context, it is essential that industrial symbiosis applications, one of the projects born for purposes such as zero waste, cleaner production, and energy-saving, are sustainable. Ensuring that these practices are sustainable has become a necessity for the conservation of natural resources and the reduction of environmental problems (Leigh \& Li, 2015). Thus, it is possible to achieve environmental development together as well as economic development. With this study, it is stated that in industrial symbiosis applications, the interests of businesses do not harm the environment and society, and environmental awareness is among the responsibilities of businesses. Ensuring the continuity of

*Corresponding author. E-mail: tamereren@gmail.com

Copyright () 2020 The Author(s). Published by Vilnius Gediminas Technical University

This is an Open Access article distributed under the terms of the Creative Commons Attribution License (http://creativecommons.org/licenses/by/4.0/), which permits unrestricted use, distribution, and reproduction in any medium, provided the original author and source are credited. 
these practices radically changes businesses and ways of doing business, leading them to build a sustainable future for themselves and the environment (Yazan \& Fraccascia, 2020).

Many criteria must be taken into account simultaneously to ensure the sustainability of these practices, which are aimed at benefiting from all aspects. These criteria may be related to both the inner world and the environment of the business. In addition to sharing with the natural environment, the partnerships of the business with other businesses are among these criteria. A proper analysis of the criteria will provide useful results in this cycle of partnerships. In this context, managers should establish an evaluation process in which these criteria are taken into account. The studies in the literature that are based on the industrial symbiosis and partnerships with the environment of the enterprises, the working frameworks focused on the development of eco-industrial parks, which are concrete realizations of the concept of industrial symbiosis. They pointed out how to formulate an eco-industrial park for optimum design (Chertow, 2000; Boons et al., 2011; Jiao \& Boons, 2014; Chertow \& Ehrenfeld, 2012; Boix et al., 2015; Yu et al., 2014). However, no studies have been found in which qualitative and quantitative evaluations of these criteria should be considered to ensure the continuity of these practices and to be sustainable. For this reason, in this study, the importance of sustainability has been pointed out to keep the companies in a competitive environment. Also, taking into consideration the natural environment, it is suggested that systems with maximum energy efficiency and minimum waste generation should be installed, or existing systems should be arranged accordingly.

In this study, multi-criteria decision-making (MCDM) methods were used to analyze the criteria affecting these processes in many ways, as sustainability is a critical point. Where multiple criteria are effective on a process or system, MCDM methods come to the fore with their analysis capabilities. In this study, the concept of industrial symbiosis is evaluated under the main criteria of economic, social, environmental, ecological industry construction, and management. In this evaluation, the analytical network process (ANP) method, which is a multi-criteria decision-making method, is used. ANP method is used as a useful tool to express the relationships between the criteria and measure their effect on the problem. The ANP method takes into account interactions and feedback between criteria. In these criteria, it was preferred to use the ANP method since it affects and is related to each other. When the results are examined, the most effective criteria/ sub-criteria are determined on the concept of industrial symbiosis. In industrial symbiosis applications, it is possible to increase the effect of the output and benefits provided by considering these criteria.

This study consists of five parts. In the first part of the study, industrial symbiosis and waste management concepts are mentioned. The studies in the literature have been included, and information has been given about the research framework of the subject. In the second part, the method used in the study is given. In the third chapter, the process of evaluating the criteria that affect the concept of industrial symbiosis is mentioned. In the last part, the interpretation of the results obtained from this evaluation is included. Also, the limits of the study and the aspects that can be improved are mentioned. Suggestions were made for future studies.

\section{Industrial symbiosis and waste management}

The deterioration of ecological balance is proceeding simultaneously with the increase of urbanization and industrialization. Providing urban sustainability has brought a different dimension to industry progress. This situation, which humanity faces today and needs to be resolved urgently, is based on the reduction of harmful wastes in the industry (Nelson \& Power, 2018). The liveability of tomorrow depends on reducing the amount of waste produced in the industry and reducing the number of resources used by establishing partnerships with each other. The phenomenon of liveability also depends on the long-term development and development of industrial partnerships. In this case, the importance of the concept of sustainability comes to the fore. The continuity of the industrial symbiosis partnerships established by the enterprises with each other also ensures the continuity of a positive impact on the environment (Teodorescu \& Danubianu, 2015). The fact that these partnerships in the industry formed the concept of industrial symbiosis, along with this concept, also required its objectives to be defined. The concept of industrial symbiosis has emerged intending to increase the efficiency of resources.

Industrial symbiosis is a useful framework that providing an increase in the economic indicators of countries, the reduction of conflicts in resource scarcity, and sustainable development. Also, it benefits the environment and reduces costs (Gümüş, 2016). Ensuring the continuity of these partnerships in the industry will return as continuous improvement in two aspects: business and environment. Sustainability of industrial symbiosis is possible by paying attention to criteria such as waste prevention, material substitution, and energy-saving (Sokka et al., 2008). In industrial symbiosis, which has critical importance on recycling, Geng et al. (2014) focused on energy savings. Overall, research results show that industrial symbiosis can effectively reduce material and energy consumption and increase overall ecological efficiency. Ocampo et al. (2015), on the other hand, defined critical levels for sustainable production.

Although industrial symbiosis is known as the unity of two different businesses, Aldrich (1999) is thought to be with similarities. It is thought that the similar structure of the enterprises may lead to their longevity. Because, as the number of common points that will benefit, the togetherness will become stronger. In some studies in the literature, they pointed out that the continuity of these partnerships should be maintained. Kurup and Stehli (2009), 
Pakarinen et al. (2010), Leigh and Li (2015), Yazan and Fraccascia (2020), and Bansal and Mcknight (2009) have examined how industrial symbiosis practices can be more sustainable. They aimed to anticipate potential costs and increase benefits in the application areas built on basic sustainability principles. Studies focus mainly on the field of application they specifically address. Thus, suggestions were made to develop business strategies in sustainable industrial symbiosis applications. No studies have been found in which these suggestions are evaluated based on criteria and using weighing methods by reflecting subjective opinions.

There are different studies in the literature about the concept of industrial symbiosis. It is seen that these studies mostly focus on industrial parks. Industrial parks, which are among industrial symbiosis applications, represent the areas where the connection between businesses is established. In these areas, enterprises can reduce waste as a result of the joint use of resources (Gümüş, 2016). Montastruc et al. (2013) drew attention to the partnership structures that should be between businesses in industrial symbiosis applications. They proposed a general model for industrial parks. According to the model, they mentioned the positive and negative aspects of the partnership structures that affect industrial symbiosis applications.

Based on the literature research, some studies benefit from the advantages of multi-criteria decision-making methods in decision-making processes. Leong et al. (2017) considered the creation of a resource network in industrial parks as a decision-making process. They offered a perspective that takes into account the preferences of each business and includes optimization of various design criteria. They modelled the problem of creating an optimum resource network with AHP based mathematical programming. Zhao et al. (2017) proposed a hybrid framework to evaluate the comprehensive utility of eco-industrial parks from a circular economy perspective. Gray-Delphi method and VIKOR method were used. Using the proposed MCDM approach, they have evaluated and rated the comprehensive benefits of eco-industrial parks. Wang et al. (2017) proposed a model for evaluating industrial symbiosis networks based on complex network structure. They evaluated important interference applications in networks with the TOPSIS method. Then, with case analysis, they touched on the results of the determination based on the community structure of the businesses and their adaptation to the community. Another study on the complex network structure is Wu et al. (2017) is his work. Wu et al. (2017) drew attention to the negativities that may occur in networks established in industrial symbiosis applications. It is stated that in complex structured networks, if the structure of the system cannot be installed appropriately, accidents may occur and cause adverse effects on the environment. The study also suggests a quantitative risk framework for the symbiosis network. Mitigation strategies are recommended for environmental risks. In Table 1, a framework has been created in terms of the theme they deal with for these studies.
Table 1. Studies by thematic features

\begin{tabular}{|l|c|c|c|}
\hline \multirow{2}{*}{\multicolumn{1}{|c|}{ Study }} & \multicolumn{2}{c|}{ Key Feature } \\
\cline { 2 - 4 } & $\begin{array}{c}\text { Eco-indust- } \\
\text { rial system } \\
\text { design }\end{array}$ & $\begin{array}{c}\text { Sustain- } \\
\text { able sym- } \\
\text { biosis }\end{array}$ & Other \\
\hline Fichtner et al. (2005) & & & + \\
\hline Kurup and Stehli (2009) & & + & \\
\hline $\begin{array}{l}\text { Bansal and Mcknight } \\
\text { (2009) }\end{array}$ & & + & \\
\hline Pakarinen et al. (2010) & & + & \\
\hline Costa et al. (2010) & & & + \\
\hline Montastruc et al. (2013) & + & & + \\
\hline Leigh and Li (2015) & & + & + \\
\hline Leong et al. (2017) & + & & + \\
\hline Zhao et al. (2017) & + & & + \\
\hline Wang et al. (2017) & & & + \\
\hline Wu et al. (2017) & + & & + \\
\hline $\begin{array}{l}\text { Yazan and Fraccascia } \\
\text { (2020) }\end{array}$ & & & + \\
\hline Song et al. (2018) & + & & + \\
\hline Kerdlap et al. (2019) & & & + \\
\hline Simboli et al. (2020) & & & + \\
\hline Kumari and Jeble (2020) & & & + \\
\hline Shah et al. (2020) & + & & + \\
\hline Raimbault et al. (2020) & & & + \\
\hline Lin et al. (2020) & & & + \\
\hline Cao et al. (2020) & & & + \\
\hline Cecchin et al. (2020) & & & + \\
\hline
\end{tabular}

Most of the studies in the literature, the importance of the concept of industrial symbiosis are emphasized. With these applications, which have a significant impact on the economy, beneficial results are obtained in recycling. With its contribution to waste management, waste generation in enterprises is reduced. Waste management is carried out by reducing and recycling waste at its source with the established industrial parks. When the waste management pyramid is taken into consideration, it is seen that action is taken to prevent the formation of waste in the first stage. Energy recovery is aimed at the reuse of the waste that is tried to be minimized. The studies under the other category draw attention to the partnerships established between the enterprises. The difficulties encountered in these partnerships and the structure of the relations are emphasized.

This study focused on the criteria that affect the sustainability of industrial symbiosis applications, unlike the studies in the literature. In this context, the contributions to the literature are summarized below:

- Within the scope of this study, attention was drawn to the sustainability of industrial symbiosis applications. Criteria affecting sustainability were determined in the study. Then, since there was an interaction between these criteria, an evaluation was made using an 
analytical method that takes these interactions into consideration.

- Secondly, this study takes an evaluation of the criteria that affect the process to ensure the sustainability of industrial symbiosis applications in the literature. Thus, it reveals its difference from the studies in the literature.

- Sustainability in industrial symbiosis is important for the continuity and permanence of applications. Continuing these partnerships established between enterprises will benefit both the environment and the business in the long term.

- In the literature, researchers focused on symbiosis applications in industry. There are a limited number of studies, which are indicated for their sustainability and ecological importance. The importance and effects of these concepts are also mentioned in these studies. This study is both a contribution and a continuation of other studies. Because there are criteria to be considered in order to ensure the sustainability concept in the symbiosis applications. It is important to evaluate these criteria analytically and turn them into meaningful results for operators. Subjective evaluations of the criteria determined with this study were transformed into quantitative data to help identify the main points to focus on.

- It was pointed out how these practices continue continuously, the criteria affecting this continuity, and how businesses should be oriented according to these criteria. It differs from the studies in the literature with these features and comes into prominence as a study that closes the gap in the literature by taking into account the opinions of the decisionmakers.

\section{Analytical network process}

Multi-criteria decision-making methods are frequently preferred by many researchers in the literature. Decision makers prefer these methods to evaluate the criteria that affect the problem they are dealing with for a purpose and to choose among the existing alternatives. There are many methods in the literature: AHP, ANP, TOPSIS, VIKOR, PROMETHEE, MOORA etc. There are also fuzzy states of these methods for decision makers.

The Analytical Network Process (ANP) method is a method that takes the interaction between the criteria out of the hierarchical structure of the analytical hierarchy process (AHP) developed by Saaty (1999). The solution process of this method, which provides more realistic and effective results, is based on the relationships between the criteria and sub-criteria and feedback. These relationships can be one-way, but also two-way (Muhcu, 2016). The steps of ANP are shown in Figure 1.

The ANP method is a method that takes into account the criteria that affect the real-life problems we consider and all the interactions between these criteria and conducts the solution process according to these relationships and provides effective results. It is among the advantages of ANP method that it offers users subjective evaluation, considering possible interactions between criteria, evaluating situations that do not have a purely hierarchical structure, allowing feedback. As in every decision-making method, in this method, situations such as being far from optimality, and changing the results with different ideas are also disadvantageous. The algorithm of the ANP method basically consists of six steps (Tinmaz, 2017).

\section{Step 1. Identification of the problem}

It is the step where the objectives in the problems we encounter and the criteria that affect these problems are defined in detail. In this step, the problem is clearly defined. The structure of the whole problem is clearly expressed. It contains detailed information on the criteria that affect the problem, the limits of the problem and how the analysis process should proceed.

\section{Step 2. Determining the dependencies between the criteria}

This is the step in which internal and external dependencies between all criteria and sub-criteria that affect the problem are taken into account. The feedback model created and the criteria are related to each other. This step allows us to clearly examine the problem addressed. The relationship of the criteria with each other is modeled with the network structure, making the evaluation of the decision makers more possible.

\section{Step 3. Creating pairwisecomparison matrices}

Thanks to the relationships between the criteria, pairwisecomparison matrices are created. The number of comparison matrices varies with the number of internal and external dependencies. While making comparison, 1-9 scale of Saaty is used. How effective one criterion is on another criterion can be evaluated in this step. Thanks to the matrix structure, the interacting criteria can be compared with each other.

Step 4. Calculation of consistency rates of comparison matrices

It is the step where the consistency of judgments of decision makers in comparison matrices is measured. Obtaining rates less than 0.10 means that the matrices created are consistent. This stage gives decision makers an opportunity to review their assessments. It provides an analysis of how consistent and rational results can be achieved on the problem.

\section{Step 5. Creating the super matrix structure}

It is the matrix structure in which all relationships including internal, external and feedback are shown. This structure shows the degree to which the criteria affect each other. If one criterion has no effect on the other criterion, this value is entered as zero.

\section{Step 6. Creating the limit matrix structure}

It is the step in which the exponential forces of the matrix are taken to calculate the long-term value of the effects of the criteria on each other. The exponential force of the 


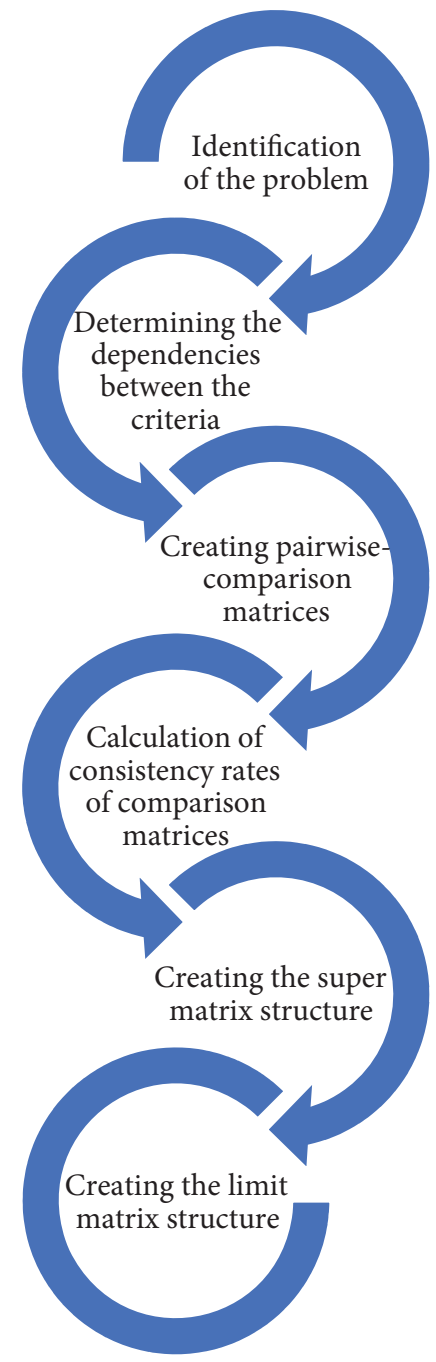

Figure 1. Steps of ANP

matrix $(2 n+1)$ is taken. The purpose of this matrix is to ensure that the importance weights are the same at some point is a randomly selected number.

The ANP method has found application opportunities in many areas by researchers in the literature. It is the reason why researchers prefer this method because it takes into account the most prominent features, relationships and interactions and plays an effective role on the outputs. Looking at the studies in the literature, Jharkharia and Shankar (2007), Hamurcu and Eren $(2016,2020)$ in the transportation sector; Bağ et al. (2012), Gür et al. (2018), Akça et al. (2018) in the health sector; Gür and Eren (2016) in performance evaluation; Özcan et al. (2017) in the energy sector; Gür et al. (2017) selection of marketing strategy, Sevinç et al. (2018); Uslu et al. (2019); Alkaş et al. (2020) applied in the field of industry 4.0.

When the studies are generally examined, it can be seen that the ANP method is used in different areas. It is understood that the researchers consider this method as a useful tool since it has the ease of application and the opportunity to obtain effective results. It is used for purposes such as evaluation of options, analysis of criteria or selection of alternatives. In this study, ANP method was used to evaluate the concept of industrial symbiosis. It is aimed to calculate the effectiveness levels of the determined criteria. Using a different method is likely to lead to a different definition of the relationship between the criteria. In this case, although it does not result in significant semantic differences in the results, it may not reflect the desired qualitative expressions. In fact, verifying the results with another decision-making method does not seem very meaningful, since the basis of each decisionmaking method is qualitative evaluation and it is far from optimality. For this problem, ANP method is the most effective tool to reflect the interactions of the criteria.

\section{Evaluation of criteria effective in industrial symbiosis sustainability}

Industrial symbiosis, which is an industrial partnership, is based on the reduction of waste ratio in enterprises and also recycling of these wastes. It contributes to their economies by increasing the utilization rate of resources. Many criteria are effective in this partnerships process. These criteria are also effective in the development and sustainability of industrial applications. In this study, the concept of industrial symbiosis is emphasized. The evaluation of the criteria affecting these processes has been taken into consideration to enable sustainable industrial symbiosis applications. 19 sub-criteria were determined under four main criteria to evaluate the sustainability of industrial symbiosis partnerships. When these criteria/sub-criteria were examined structurally, it was found that there were a connection and relationship between them. The ANP method, which is a multi-criteria decision-making method, was used to analyze these relationships and measure their effects on the concept of industrial symbiosis. The ANP method is an effective tool that models the interactions between criteria by network structure and helps to analyze feedback and criteria. In the application steps of the study, the application steps of the ANP method were followed.

\section{Step 1. Identification of the Problem}

Industrialization and rapid population growth caused the depletion of resources and environmental problems. Taking measures against environmental problems and using resources effectively without diminishing economic benefits gained an important dimension. With the concept of industrial symbiosis, resource usage among enterprises can be increased. At the same time, waste generation can be minimized by using more efficient resources. Many criteria are considered to realize these applications. In this study, the criteria that affect the concept and applications of industrial symbiosis are evaluated. Urban planning, design, and management activities are also affected by these practices where wastes are used as a resource. The criteria that affect these processes indirectly affecting each other have been determined with the help of literature studies and experts. These experts are five people. It consists of 
academicians working in the field of environment and business and investors who want to invest in this field. The views of these people were collected separately and combined with the geometric mean. In the process of defining the criteria, assistance was obtained from experts who are experts in waste management. There are four main criteria and 19 sub-criteria. The main criteria are economic, social, environmental, and management. The main criteria of the economy are annual average growth rate of the industry, industrial assets, and the value of high-tech output, the contribution of scientific and technological progress to Gross domestic product (GDP). GDP is one of several criteria of a country's economic size.

The degree of incentive to increase employment and government income sub-criteria are included under the main criterion of social. Energy consumption, water consumption, industrial water recycling rate, energy recycling rate, toxic and hazardous waste emissions, waste treatment plants, $\mathrm{CO}_{2}$ emissions, a recycling rate of industrial solid wastes, recycled water reuse rate, the functionality of environmental management system subcriteria are included under the main criterion of environmental. Implementation of the business management system, ISO14001 certification of the enterprises in the park, and eco-industrial training sub-criteria are included under the main criterion of management. These criteria are shown in Table 2.

When the structure of the criteria is considered, the criteria that should be focused on in the enterprises for industrial symbiosis applications and how to ensure the sustainability of these applications are obtained. Businesses try to understand which criteria come to the forefront in industrial symbiosis and which points should be paid to attend. Having become aware that natural resources are consumable, managers have begun to pay attention to the environmental impact of the products and activities they offer. Another condition of competitiveness has started to be measured with the value given to the environment and humanity. In this case, with the criteria based on Zhao et al. (2017) study, enterprises will be able to determine which points they will provide sustainability for industrial symbiosis partnerships.

\section{Step 2. Determination of dependencies between criteria}

The ANP method takes into account interactions and dependencies between criteria. The ANP method was used in this study because of the interdependence of the criteria in the problem addressed. The interaction of the criteria with each other and the relationship between them are modelled as a network structure. The network structure is shown in Figure 2.

When the network structure shown in Figure 2 is considered, it is seen that all the main criteria interact in themselves. As a result of these interactions, the concept and applications of industrial symbiosis are shaped. Industrial symbiosis is the application that increases resource efficiency through by-product exchange between different processes and industries. In these applications, energy flows between diversified processes and differentiating industries. Dimensional properties of energy flow are reflected in this network structure.

\section{Step 3. Creating pairwise comparison matrices}

Pairwise comparison matrices were created according to their interactions between criteria and sub-criteria based on the network structure shown in Figure 2. Saaty's 1-9 scale was used to evaluate these comparison matrices. According to this scale, importance levels are determined according to each other. Evaluation of pairwise comparison matrices was done with the help of experts in waste management. The opinions of experts on these matrices are combined with the geometric mean. Table 3 shows an example comparison matrix.

As in Table 2, other comparison matrices are formed according to the interactions between them. The criteria or sub-criteria according to scale 1-9 were evaluated according to each other.

Table 2. Criteria and sub-criteria

\begin{tabular}{|l|l|}
\hline \multicolumn{2}{|c|}{ P1: ECONOMIC } \\
\hline \multicolumn{2}{|c|}{ CRITERIA/SUB CRITERIA } \\
\hline \multicolumn{1}{|c|}{ P2: SOCIAL } & \multicolumn{1}{c|}{ P4: ENVIRONMENTAL } \\
\hline C1: Annual average growth rate of industry & C10: Energy consumption \\
\hline C2: Industrial assets & C11: Water consumption \\
\hline C3: The value of high-tech output & C12: Industrial water recycling rate \\
\hline C4: The contribution of scientific and technological progress to GDP & C13: Energy recycling rate \\
\hline & C14: Toxing and hazardous waste emissions \\
\hline C5: Degree of incentive to increase employment & C15: Waste treatment plants \\
\hline C6: Government income & C16: CO ${ }_{2}$ emissions \\
\hline & C17: Recycling rate of industrial solid wastes \\
\hline C7: Implementation of business management system & C18: Recycled water reuse rate \\
\hline C8: ISO14001 certification of the enterprises in the park & C19: Functionality of environmental management system \\
\hline C9: Eco-industrial training & \\
\hline
\end{tabular}


CRITERIA / SUB-CRITERIA

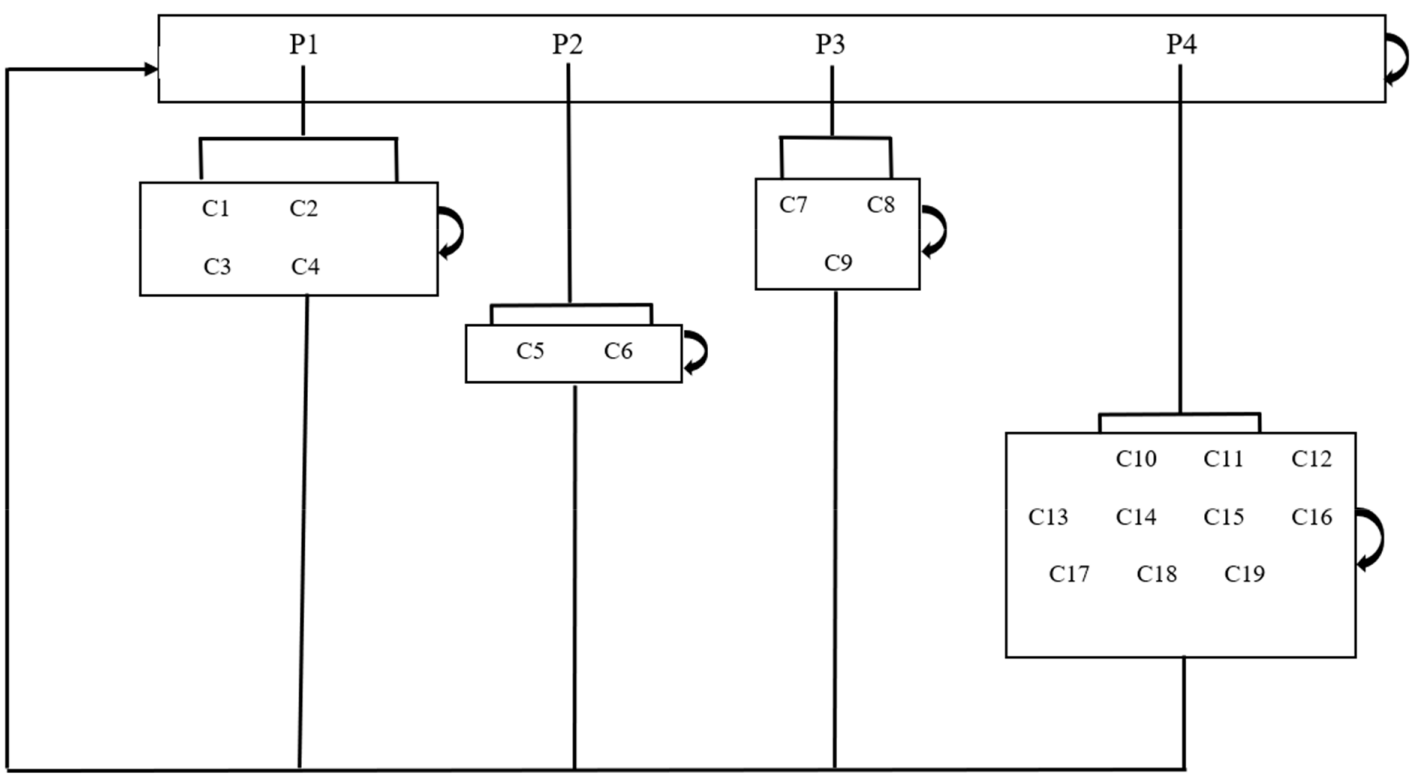

Figure 2. Network structure between criteria/sub-criteria

Table 3. Comparisons "K9" node in "Environmental" cluster

\begin{tabular}{|l|l|l|l|l|l|l|l|l|l|l|l|l|l|l|l|l|l|l|}
\hline Energy consumption & 9 & 8 & 7 & 6 & 5 & 4 & 3 & 2 & 1 & 2 & 3 & 4 & 5 & 6 & 7 & 8 & 9 & Industrial water recycling rate \\
\hline Energy consumption & 9 & 8 & 7 & 6 & 5 & 4 & 3 & 2 & 1 & 2 & 3 & 4 & 5 & 6 & 7 & 8 & 9 & Waste treatment plants \\
\hline Energy consumption & 9 & 8 & 7 & 6 & 5 & 4 & 3 & 2 & 1 & 2 & 3 & 4 & 5 & 6 & 7 & 8 & 9 & $\mathrm{CO}_{2}$ emissions \\
\hline Energy consumption & 9 & 8 & 7 & 6 & 5 & 4 & 3 & 2 & 1 & 2 & 3 & 4 & 5 & 6 & 7 & 8 & 9 & Recycled water reuse rate \\
\hline Industrial water recycling rate & 9 & 8 & 7 & 6 & 5 & 4 & 3 & 2 & 1 & 2 & 3 & 4 & 5 & 6 & 7 & 8 & 9 & Waste treatment plants \\
\hline Industrial water recycling rate & 9 & 8 & 7 & 6 & 5 & 4 & 3 & 2 & 1 & 2 & 3 & 4 & 5 & 6 & 7 & 8 & 9 & $\mathrm{CO}_{2}$ emissions \\
\hline Industrial water recycling rate & 9 & 8 & 7 & 6 & 5 & 4 & 3 & 2 & 1 & 2 & 3 & 4 & 5 & 6 & 7 & 8 & 9 & Recycled water reuse rate \\
\hline Waste treatment plants & 9 & 8 & 7 & 6 & 5 & 4 & 3 & 2 & 1 & 2 & 3 & 4 & 5 & 6 & 7 & 8 & 9 & $\mathrm{CO}_{2}$ emissions \\
\hline Waste treatment plants & 9 & 8 & 7 & 6 & 5 & 4 & 3 & 2 & 1 & 2 & 3 & 4 & 5 & 6 & 7 & 8 & 9 & Recycled water reuse rate \\
\hline $\mathrm{CO}_{2}$ emissions & 9 & 8 & 7 & 6 & 5 & 4 & 3 & 2 & 1 & 2 & 3 & 4 & 5 & 6 & 7 & 8 & 9 & Recycled water reuse rate \\
\hline
\end{tabular}

Table 4. Criteria/Sub-criteria weights

\begin{tabular}{|c|c|c|c|}
\hline Main Criteria & Number & Sub Criteria & Weights \\
\hline \multirow{4}{*}{ Economic $(0.256)$} & $\mathrm{C} 1$ & Annual average growth rate of industry & 0.077 \\
\hline & $\mathrm{C} 2 \mathrm{:}$ & Industrial assets & 0.3245 \\
\hline & C3: & The value of high-tech output & 0.413 \\
\hline & C4: & The contribution of scientific and technological progress to GDP & 0.264 \\
\hline \multirow{2}{*}{ Social $(0.145)$} & C5: & Degree of incentive to increase employment & 0.328 \\
\hline & C6: & Government income & 0.672 \\
\hline \multirow{3}{*}{ Management (0.33) } & C7: & Implementation of business management system & 0.272 \\
\hline & C8: & ISO14001 certification of the enterprises in the park & 0.349 \\
\hline & C9: & Eko-industrial training & 0.379 \\
\hline \multirow{10}{*}{ Environmental (0.27) } & C10: & Energy consumption & 0.082 \\
\hline & C11: & Water consumption & 0.060 \\
\hline & C12: & Industrial water recycling rate & 0.101 \\
\hline & C13: & Energy recycling rate & 0.077 \\
\hline & C14: & Toxic and hazardous waste emissions & 0.117 \\
\hline & C15: & Waste treatment plants & 0.092 \\
\hline & C16: & $\mathrm{CO}_{2}$ emissions & 0.205 \\
\hline & C17: & Recycling rate of industrial solid wastes & 0.153 \\
\hline & C18: & Recycled water reuse rate & 0.039 \\
\hline & C19: & Functionality of environmental management system & 0.074 \\
\hline
\end{tabular}


Step 4. Calculation of consistency ratios of comparison matrices

The consistency ratio is calculated to measure the consistency and accuracy of the pairwise comparison matrices. In this study, the consistency ratio of all pairwise comparison matrices was calculated and found to be less than 0.1. This suggests that decision-makers consistently compare the criteria.

\section{Step 5. Obtaining the weights of the criteria/sub-criteria}

After the network structure, the interaction rates of the criteria are determined from pairwise comparison matrices according to their interactions. Table 4 shows the weights of the criteria/sub-criteria.

\subsection{Managerial insight}

When the main criteria for a sustainable industrial symbiosis application are considered, the management criterion is the highest weighted criterion. It is important to establish a system based on business management philosophy in symbiosis application and to provide training for the execution of the application for both managers and employees. Besides, the enterprises included in the system must be provided with the environmental management system certifications in terms of the continuity of the system.

Environmental criteria emerged as the second important criteria in the main criteria. When the sub-criteria are evaluated, the importance level of $\mathrm{CO} 2$ emission, solid waste recycling rate, toxic and hazardous waste prevention, and ensuring the recycling of wastewater as usable water are higher. When these four criteria are evaluated, it is seen that these are the criteria for protecting the environment. For a sustainable industrial symbiosis system, measures regarding waste recycling and hazardous waste prevention should be taken and targeted primarily at the establishment of the system.

Another criterion as important as the environment is the economy criterion. It is noteworthy in the sub-criteria that companies turn to high-tech output production in terms of sustainability of the system. The companies in the system should be directed to the production of these products. The high rate of output provided by companies to the GDP and the industrial assets they hold are also important criteria for the sustainability of the companies and the sustainability of the industrial symbiosis system.

From a social perspective, it is possible to generate an income increase from the sources as the companies use their resources more efficiently. In this case, it increases the contribution to the government. Sustainability can be provided by getting government support with the increase in government income. However, increasing employment has less impact on sustainability.

\section{Conclusion and recommendations}

The increase in consumption and the sensible increase in climate change have brought uneasiness about the availability of resources. Strategies are investigated to optimize resources in the industry, which has a large share of energy consumption. For this purpose, enterprises aim to enable the use of raw materials between each other and to reduce waste production. Structures designed to be the waste of one enterprise and the raw material of the other enterprise are called industrial partnerships or industrial symbiosis. Negative impacts on the environment are significantly reduced in the enterprises where this model of partnerships is established. Sustaining industrial partnerships due to the sustainability of environmental resources is also an important criteria in terms of socio-economic and environmental protection all over the world. In this study, industrial symbiosis and industrial symbiosis applications are emphasized. The criteria that have an impact on the sustainability of industrial symbiosis applications have been determined. It has been noted that industrial symbiosis applications have started to form the building blocks of the decisions of the enterprises at the managerial level. In addition to this, it is emphasized that the criteria which affect the applications of industrial symbiosis should be evaluated. The ANP method, one of the multicriteria decision-making methods that allows quantitative and qualitative analysis of the criteria, was used in the evaluation process.

The ANP method used in the study allows the users to analyze the complex and related situations. In cases with a complex structure, there may be a dependency situation among the criteria that affect the problem. The existence of these addictions can lead to a structure that is affected by each other and is fed back from this interaction. For this reason, it is important to model this situation and to determine the relationships of the criteria that affect the problem. The reason for using the ANP method in the problem is to analyze these relationships and get correct results. The steps of the ANP method allow qualitative decisions to be expressed as quantitative values. Among the reasons why users prefer the ANP method are the dependencies between the criteria.

Multi-criteria decision-making methods enable decision-makers to evaluate the process in a multi-dimensional way. In this study, the criteria affecting the process were analyzed according to each other. The interactions of the criteria and their relationships within each other are modelled by the network structure. The paired comprise on matrices formed by the network structure and the interaction criteria were evaluated according to each other. According to the results, it is seen that the managerial policies and environmental conditions are among the basic building blocks that play a role in establishing these partnerships. The government's financial and moral support for these practices in the industrial sector plays an important role in achieving the sustainability goals of industrial partnerships. Also, the technologies used by the enterprises will help to increase the efficiency of these partnerships. Furthermore, examining the role of technology and ecological awareness on employees and 
enterprises will support the development of applications in the industry.

Businesses can draw a road map on how to use their resources efficiently with the results obtained in the study. Besides, companies that provide cooperation will be able to establish new relationships that benefit them under the current circumstances. Thus, interactions not only at the inter-enterprise level but also at the regional or global level can increase and benefit. When the output of one enterprise becomes the input of the other enterprise, savings in raw material and energy inputs can increase. The continuity of all these benefits depends on the longevity of these partnerships. For this, the key criteria of these applications should be analyzed well, and necessary attention should be given to the continuity of the relations.

In the subsequent studies, researchers can examine the interaction between them by reducing the industrial symbiosis to the basis of enterprises. They can investigate the points that companies in the same market have difficulty in forming these partnerships and examine the reasons for these difficulties. Besides, in future studies, the effects of applications on the productivity of businesses can be measured by taking into account the costs or the reliability analysis of these criteria can be done with statistical methods.

\section{References}

Aldrich, H. (1999). Organizations evolving. Sage.

Aissani, L., Lacassagne, A., Bahers, J. B., \& Féon, S. L. (2019). Life cycle assessment of industrial symbiosis: A critical review of relevant reference scenarios. Journal of Industrial Ecology, 23, 972-985. https://doi.org/10.1111/jiec.12842

Alkaș, O., Gür, Ş., \& Eren, T. (2020). Küçük ve Orta Ölçekli İşletmelerde E-Tedarik Zincirinin Benimsenmesinde Etkili Olan Faktörlerin Değerlendirilmesi. Düzce Üniversitesi Bilim ve Teknoloji Dergisi, 8, 511-521. https://doi.org/10.29130/dubited.601932

Akça, N., Sönmez, S., Gür, Ş., Yılmaz, A., \& Eren, T. (2018). Financial manager selection with analytic network process method in public hospitals. Optimum Journal of Economics and Management Sciences, 5(2), 133-146. https://doi.org/10.17541/optimum.390536

Bağ, N., Özdemir, M., \& Eren, T. (2012). 0-1 nurse scheduling solution with goal programming and ANP method. International Journal of Engineering Research and Development, 4(1), 2-6.

Bansal, P., \& McKnight, B. (2009). Looking forward, pushing back and peering sideways: analyzing the sustainability of industrial symbiosis. Journal of Supply Chain Management, 45(4), 26-37. https://doi.org/10.1111/j.1745-493X.2009.03174.x

Boix, M., Montastruc, L., Azzaro-Pantel, C., \& Domenech, S. (2015). Optimization methods applied to the design of ecoindustrial parks: a literature review. Journal of Cleaner Production, 87, 303-317.

https://doi.org/10.1016/j.jclepro.2014.09.032

Boons, F., Spekkink, W., \& Mouzakitis, Y. (2011). The dynamics of industrial symbiosis: a proposal for a conceptual framework based upon a comprehensive literature review. Journal of Cleaner Production, 19(9-10), 905-911.

https://doi.org/10.1016/j.jclepro.2011.01.003
Cao, X., Wen, Z., Xu, J., De Clercq, D., Wang, Y., \& Tao, Y. (2020). Many-objective optimization of technology implementation in the industrial symbiosis system based on a modified NSGA-III. Journal of Cleaner Production, 245, 118810. https://doi.org/10.1016/j.jclepro.2019.118810

Cecchin, A., Salomone, R., Deutz, P., Raggi, A., \& Cutaia, L. (2020). Relating industrial symbiosis and circular economy to the sustainable development debate. In R. Salomone, A. Cecchin, P. Deutz, A. Raggi, \& L. Cutaia (Eds.), Industrial symbiosis for the circular economy (pp. 1-25). Springer, Cham. https://doi.org/10.1007/978-3-030-36660-5_1

Chertow, M. R. (2000). Industrial symbiosis: literature and taxonomy. Annual Review of Energy and the Environment, 25(1), 313-337. https://doi.org/10.1146/annurev.energy.25.1.313

Chertow, M. R. (2007). "Uncovering” industrial symbiosis. Journal of Industrial Ecology, 11(1), 11-30.

https://doi.org/10.1162/jiec.2007.1110

Chertow, M., \& Ehrenfeld, J. (2012). Organizing self-organizing systems: Toward a theory of industrial symbiosis. Journal of Industrial Ecology, 16(1), 13-27. https://doi.org/10.1111/j.1530-9290.2011.00450.x

Costa, I., Massard, G., \& Agarwal, A. (2010). Waste management policies for industrial symbiosis development: case studies in European countries. Journal of Cleaner Production, 18(8), 815-822. https://doi.org/10.1016/j.jclepro.2009.12.019

Fichtner, W., Tietze-Stöckinger, I., Frank, M., \& Rentz, O. (2005). Barriers of inter organisational environmental management: two case studies on industrial symbiosis. Progress in Industrial Ecology, an International Journal, 2(1), 73-88. https://doi.org/10.1504/PIE.2005.006778

Geng, Y., Liu, Z., Xue, B., Dong, H., Fujita, T., \& Chiu, A. (2014). Emergy-based assessment on industrial symbiosis: a case of Shenyang Economic and Technological Development Zone. Environmental Science and Pollution Research, 21(23), 1357213587. https://doi.org/10.1007/s11356-014-3287-8

Gür, Ş., Uslu, B., Eren, T., Akça, N., Yılmaz, A., \& Sönmez, S. (2018). Evaluation of operating room performance in hospitals by using analytic network process. Gazi Journal of Health Sciences, 3(3), 10-25.

Gür, Ş., Bedir, N., \& Eren, T. (2017). Selection of marketing strategies with analytical network process and PROMETHEE method for medium sized business in food sector. Nevsehir Journal of Science and Technology, 6(1), 79-92. https://doi.org/10.17100/nevbiltek.331412

Gür Ş., \& Eren, T. (2016). Evaluation of factors affecting the performance of businesses by analytical network process method. Trakya University Journal of Faculty of Economics and Administrative Sciences, 5(2), 80-97.

Gümüş, T. Ç. (2016). Development of a cleaner production and industrial symbiosis system for eco-industrial parks [Master thesis]. TOBB University of Economics and Technology Institute of Science.

Hamurcu, M., \& Eren, T. (2016, October 13-15). Selection of monorail technology for urban transportation in Ankara with analytical network process. In International Symposium on Railway Systems Engineering (pp. 559-566). Karabük.

Hamurcu, M., \& Eren, T. (2020). Electric bus selection with multicriteria decision analysis for green transportation. Sustainability, 12(7), 2777. https://doi.org/10.3390/su12072777

Jharkharia, S., \& Shankar, R. (2007). Selection of logistics service provider: An analytic network process (ANP) approach. Omega, 35(3), 274-289.

https://doi.org/10.1016/j.omega.2005.06.005 
Jiao, W., \& Boons, F. (2014). Toward a research agenda for policy intervention and facilitation to enhance industrial symbiosis based on a comprehensive literature review. Journal of Cleaner Production, 67, 14-25.

https://doi.org/10.1016/j.jclepro.2013.12.050

Kerdlap, P., Low, J. S. C., Steidle, R., Tan, D. Z. L., Herrmann, C., \& Ramakrishna, S. (2019). Collaboration platform for enabling industrial symbiosis: Application of the industrial-symbiosis life cycle analysis engine. Procedia CIRP, 80, 655-660. https://doi.org/10.1016/j.procir.2019.01.081

Kurup, B., \& Stehlik, D. (2009). Towards a model to assess the sustainability implications of industrial symbiosis in eco-industrial parks. Progress in Industrial Ecology, an International Journal, 6(2), 103-119.

https://doi.org/10.1504/PIE.2009.029077

Kumari, S., \& Jeble, S. (2020). Waste management through industrial symbiosis: case study approach. Latin American Journal of Management for Sustainable Development, 5(1), 37-46. https://doi.org/10.1504/LAJMSD.2020.10027398

Leigh, M., \& Li, X. (2015). Industrial ecology, industrial symbiosis and supply chain environmental sustainability: a case study of a large UK distributor. Journal of Cleaner Production, 106, 632-643. https://doi.org/10.1016/j.jclepro.2014.09.022

Leong, Y. T., Lee, J. Y., Tan, R. R., Foo, J. J., \& Chew, I. M. L. (2017). Multi-objective optimization for resource network synthesis in eco-industrial parks using an integrated analytic hierarchy process. Journal of Cleaner Production, 143, 12681283. https://doi.org/10.1016/j.jclepro.2016.11.147

Lin, Y., Liu, Z., Liu, R., Yu, X., \& Zhang, L. (2020). Uncovering driving forces of co-benefits achieved by eco-industrial development strategies at the scale of industrial park. Energy \& Environment, 31(2), 275-290.

https://doi.org/10.1177/0958305X19857908

Montastruc, L., Boix, M., Pibouleau, L., Azzaro-Pantel, C., \& Domenech, S. (2013). On the flexibility of an ecoindustrial park (EIP) for managing industrial water. Journal of Cleaner Production, 43, 1-11.

https://doi.org/10.1016/j.jclepro.2012.12.039

Muhcu, Ü. (2016). Determining the importance level of critical success factors affecting humanitarian supply chain: Analytic network process application [Master thesis]. Karadeniz Technical University, Institute of Social Sciences.

Nelson, J. A., \& Power, M. (2018). Ecology, sustainability, and care: Developments in the field. Feminist Economics, 24(3), 80-88. https://doi.org/10.1080/13545701.2018.1473914

Ocampo L. A., Vergara, V. G. N., Impas, C. G., Tordillo, J. A. S., \& Pastoril, J. S. (2015). Identifying critical indicators in sustainable manufacturing using analytic hierarchy process (AHP). Journal of Manufacturing and Industrial Engineering, 14(3-4), 1-8. https://doi.org/10.12776/mie.v14i3-4.444

Özcan, E. C., Özcan, N. A., \& Eren, T. (2017). Selection of the solar power plants with CSP technologies by combined ANPPROMETHEE approach. Başkent University Journal of Faculty of Commercial Sciences, 1(1), 18-44.

Pakarinen, S., Mattila, T., Melanen, M., Nissinen, A., \& Sokka, L. (2010). Sustainability and industrial symbiosis - The evolution of a Finnish forest industry complex. Resources, Conservation and Recycling, 54(12), 1393-1404.

https://doi.org/10.1016/j.resconrec.2010.05.015

Raimbault, J., Broere, J., Somveille, M., Serna, J. M., Strombom, E., Moore, C., Zhu, B., \& Sugar, L. (2020). A spatial agent-based model for simulating and optimizing networked eco-industrial systems. Resources, Conservation and Recycling, 155, 104538. https://doi.org/10.1016/j.resconrec.2019.104538
Saaty, T. L. (1999, August). Fundamentals of the analytic network process. In Proceedings of the 5th International Symposium on the Analytic Hierarchy Process (pp. 12-14).

Shah, I. H., Behera, S. K., Rene, E. R., \& Park, H. S. (2020). Integration of bio refineries for waste valorization in Ulsan EcoIndustrial Park, Korea. In Waste Biorefinery (pp. 659-678). Elsevier. https://doi.org/10.1016/B978-0-12-818228-4.00024-1

Sevinç, A., Gür, Ş., \& Eren, T. (2018). Analysis of the difficulties of SMEs in industry 4.0 applications by analytical hierarchy process and analytical network process. Processes, 6(12), 264. https://doi.org/10.3390/pr6120264

Simboli, A., Taddeo, R., Raggi, A., \& Morgante, A. (2020). Structure and relationships of existing networks in view of the potential industrial symbiosis development. In R. Salomone, A. Cecchin, P. Deutz, A. Raggi, \& L. Cutaia (Eds.), Industrial symbiosis for the circular economy (pp. 57-71). Springer, Cham. https://doi.org/10.1007/978-3-030-36660-5_4

Sokka, L., Melanen, M., \& Nissinen, A. (2008). How can the sustainability of industrial symbioses be measured?. Progress in Industrial Ecology, an International Journal, 5(5-6), 518-535. https://doi.org/10.1504/PIE.2008.023414

Song, X., Geng, Y., Dong, H., \& Chen, W. (2018). Social network analysis on industrial symbiosis: A case of Gujiaoecoindustrial park. Journal of Cleaner Production, 193, 414-423. https://doi.org/10.1016/j.jclepro.2018.05.058

Teodorescu, C., \& Danubianu, M. (2015). Industrial symbiosis, ecoefficiency, sustainability a case study. Present Environment and Sustainable Development, 9(1), 169-179.

https://doi.org/10.1515/pesd-2015-0012

Tinmaz, M. (2017). Selection among technology retail company using fuzzy analytic network process methodology [Master thesis]. Sakarya University Graduate School of Natural and Applied Sciences.

Uslu, B., Gür, Ş., \& Eren, T. (2019). Evaluation of best strategy selection for industry 4.0 application by ANP and TOPSIS methods. Eskisehir Technical University Journal of Science and Technology B-Theoretical Sciences, 7(1), 13-38.

Yazan, D. M., \& Fraccascia, L. (2020). Sustainable operations of industrial symbiosis: an enterprise input-output model integrated by agent-based simulation. International Journal of Production Research, 58(2), 392-414. https://doi.org/10.1080/00207543.2019.1590660

Yu, C., Davis, C., \& Dijkema, G. P. (2014). Understanding the evolution of industrial symbiosis research: A bibliometric and network analysis (1997-2012). Journal of Industrial Ecology, 18(2), 280-293. https://doi.org/10.1111/jiec.12073

Zhao, H., Zhao, H., \& Guo, S. (2017). Evaluating the comprehensive benefit of eco-industrial parks by employing multi-criteria decision-making approach for circular economy. Journal of Cleaner Production, 142, 2262-2276.

https://doi.org/10.1016/j.jclepro.2016.11.041

Wang, Z., Jiang, Y., Huang, Y., \& Jia, X. (2017). Complex network method towards evaluating industrial symbiosis. Chemical Engineering Transactions, 61, 169-174.

https://doi.org/10.1016/j.ces.2017.06.033

World Energy Council. (2018). World Energy Trilemma Index 2018. https://www.worldenergy.org/assets/downloads/WorldEnergy-Trilemma-Index-2018.pdf

Wu, J., Pu, G., Ma, Q., Qi, H., \& Wang, R. (2017). Quantitative environmental risk assessment for the iron and steel industrial symbiosis network. Journal of Cleaner Production, 157, 106-117. https://doi.org/10.1016/j.jclepro.2017.04.094 